\title{
Program Kesiapsiagaan Tsunami Usaha Hotel di Kawasan Pariwisata Anyer, Provinsi Banten
}

\author{
Shandra Rama Panji Wulung ${ }^{*}$, Cep Ubad Abdullah ${ }^{2}$ \\ ${ }^{1,2}$ Universitas Pendidikan Indonesia \\ *Email:wulung@upi.edu
}

\begin{abstract}
The increasing number of tourism activities and the vulnerability of Anyer tourism site located in Selat Sunda coast to tsunami has led hotel industry to develop preparedness programs as an attempt to reduce the risks of disaster. Tourist safety and security are the main focus of hotel industry in creating Selat Sunda coast as a tsunami resistant area. This study aims to identify programs of preparedness of tsunami for hotel industry in Anyer tourism site. In addition, this study also identifies programs created by Banten Provincial and Serang Regional governments. The study had been carried out for 6 months among 8 hotels around Anyer. The primary data of the study were collected through observation, interview, and questionnaire while the secondary data were acquired through review of previous literature and local government policies. The data were analyzed in a descriptive qualitative way. The results showed that the hotel industry around Anyer have not been implementing non-structural preparedness concepts in accordance with the mitigation concepts of tsunami. The absence of such standards of operational procedure leads to the high number of fatalities. It is expected that this study is able to contribute to disaster management for hotel industries in tsunami resistant areas, considering limited studies in relation to tsunami preparedness for hotel industry. Despite the low number of hotels implementing ideal disaster preparedness programs, this study is expected to be able to initiate the hotels to start such programs.
\end{abstract}

Keywords: Anyer, Disaster preparedness, Tourism destination. Tsunami ready hotel

\begin{abstract}
Abstrak
Tingginya aktivitas wisata dan rentannya kawasan pariwisata Anyer di pesisir Selat Sunda terhadap tsunami memicu usaha hotel untuk mengembangkan program kesiapsiagaan sebagai upaya pengurangan risiko bencana. Keamanan dan keselamatan wisatawan menjadi fokus utama usaha hotel dalam mewujudkan kawasan pesisir Selat Sunda sebagai kawasan yang tahan akan tsunami. Penelitian ini bertujuan untuk mengidentifikasi program kesiapsiagaan tsunami pada usaha hotel di kawasan pariwisata Anyer. Selain itu, diidentifikasi juga program pemerintah daerah Provinsi Banten dan Kabupaten Serang. Penelitian ini dilakukan selama enam bulan pada delapan usaha hotel di kawasan pariwisata Anyer. Data primer diperoleh melalui observasi, wawancara, dan kuesioner, sementara data sekunder didapatkan melalui studi pada kajian terdahulu dan kebijakan pemerintah daerah. Analisis data pada penelitian ini menggunakan analisis kualitatif deskriptif. Hasil penelitian menunjukkan bahwa usaha hotel di kawasan pariwisata Anyer belum menerapkan konsep kesiapsiagaan non struktural yang sesuai konsep hotel siaga tsunami sebelum terjadinya Tsunami Selat Sunda. Tidak adanya prosedur standar operasional tsunami menjadi penyebab utama tingginya korban jiwa. Penelitian ini diharapkan mampu berkontribusi pada manajemen bencana bagi usaha hotel di kawasan rawan tsunami, mengingat terbatasnya kajian terkait kesiapsiagaan tsunami bagi usaha hotel. Meskipun sebagian besar usaha hotel di kawasan pariwisata Anyer cenderung belum menerapkan program kesiapsiagaan tsunami, dengan adanya penelitian ini diharapkan usaha hotel memulai mempersiapkan program kesiapsiagaan tsunami dalam menunjang terwujudnya hotel siaga tsunami
\end{abstract}

Keywords: Anyer, Destinasi pariwisata, Hotel Siaga Tsunami, Kesiapsiagaan bencana 


\section{Pendahuluan}

Selama satu dekade terakhir sejumlah bencana alam sangat mempengaruhi destinasi pariwisata di Indonesia, mencakup gempa bumi yang melanda kawasan pariwisata di Pantai Senggigi, Lombok (Maryanti et al., 2019; Wahyuningtyas et al., 2020), gempa yang diikuti tsunami di Palu (Aprilia \& Stiv, 2018; Darwati et al., 2019), serta Tsunami di Selat Sunda yang berdampak pada kunjungan wisatawan di kawasan pariwisata Anyer, Carita, dan Tanjung Lesung dua tahun terakhir (Shalih, 2019; Wulung, Abdullah, \& Ervina, 2019; Wulung \& Abdullah, 2020). Bencana alam tersebut diindikasikan oleh letak Indonesia yang berada pada jalur Cincin Api Pasifik dan kawasan rawan bencana tsunami, gempa bumi, dan banjir. Menciptakan hubungan antara pariwisata dan pengurangan risiko bencana sangat penting di daerah yang sangat ketergantungan pada aktivitas pariwisata (Becken \& Hughey, 2013), terutama keselamatan bagi wisatawan yang menginap selama di destinasi pariwisata (AlBattat \& MatSom, 2019; AlBattat \& MatSom, 2013; Enz \& Taylor, 2002). Usaha hotel tidak dapat berkembang di destinasi pariwisata yang rentan terhadap bencana (Reisinger \& Mavondo, 2005). Kawasan pariwisata Anyer sangat rentan akan terjadinya bencana alam, hal tersebut terbukti oleh adanya bencana Tsunami Selat Sunda pada akhir 2018 (Cahyadi, 2019; Wulung \& Abdullah, 2020).

Terjadinya bencana Tsunami Selat Sunda dipicu akibat pasang tinggi dan longsor bawah laut dari erupsi Gunung Anak Krakatau, bencana tersebut menyebabkan kerugian ekonomi dan menyebabkan efek domino berupa pembatalan kunjungan wisatawan yang menginap di kawasan pariwisata. Untuk menindaklanjuti bencana yang telah dan akan terjadi serta mendukung kegiatan kepariwisataan, berbagai gagasan diwujudkan oleh para pemangku kepentingan di kawasan pariwisata pesisir Banten melalui pemahaman terkait penanggulangan bencana pada usaha hotel. Keberhasilan dan kegagalan usaha sangat tergantung pada kemampuan dalam memberikan rasa aman pada wisatawan yang menginap (AlBattat \& MatSom, 2013; Brown et.al., 2017; Ritchie et.al., 2011).

Hotel berbintang di kawasan pariwisata Anyer telah berupaya mengurangi risiko tsunami melalui program-program mitigasi dan kesiapsiagaan pasca Tsunami Selat Sunda di akhir 2018. Hal tersebut bertujuan menjadikan usaha hotel siaga tsunami (tsunami ready hotel), sehingga diharapkan dapat mengurangi korban jiwa serta dampak terburuk lainnya ketika terjadinya tsunami di masa mendatang. Melakukan persiapan akan jauh lebih efektif daripada hanya mengandalkan proses pemulihan pasca bencana di destinasi pariwisata (Faulkner, 2001; Faulkner \& Vikulov, 2001).

Tsunami merupakan salah satu ancaman bencana untuk banyak wilayah pesisir di Indonesia. Jenis-jenis tsunami berdasarkan waktu terjadinya dibedakan menjadi dua, yakni tsunami jarak dekat/ lokal (near field/ local field tsunami) dan tsunami jarak jauh (far field tsunami). Tsunami jarak dekat yakni tsunami yang terjadi kurang dari $100 \mathrm{~km}$ dari episenter gempa bumi, tsunami ini bisa sampai ke pantai hanya dalam hitungan menit (IOC \& UNESCO, 2012). Risiko tsunami dapat dikurangi dengan langkah-langkah yang disebut sebagai pengurangan risiko bencana (PRB) tsunami, yakni dengan cara mitigasi bencana dan meningkatkan kesiapsiagaan (BNPB, 2013).

Upaya mengurangi dampak bencana dapat dilakukan dengan berbagai upaya pengurangan risiko bencana, mulai dari upaya pengurangan tingkat kerentanan sampai upaya peningkatan kapasitas. Salah satu bentuk peningkatan kapasitas yang wajib dilakukan di kawasan rawan bencana adalah kesiapsiagaan, karena pada kenyataannya tidak semua bencana dapat dicegah ataupun ditangani dengan aktivitas mitigasi yang komprehensif. Kesiapsiagaan merupakan pengetahuan dan kapasitas yang dikembangkan oleh pemerintah, profesional kebencanaan, 
komunitas dan individu untuk secara efektif mengantisipasi, menanggapi, dan mengatasi kejadian bencana (UNISDR, 2009). Kesiapsiagaan meliputi kemampuan untuk memahami dan menafsirkan peringatan dini tsunami, untuk mengatur tindakan evakuasi serta tindakan lain yang harus diambil untuk meminimalkan kemungkinan hilangnya nyawa dan kerusakan yang terjadi selama bencana tsunami berlangsung, dan melakukan prosedur penyelamatan yang tepat waktu dan efektif. Kesiapsiagaan tsunami akan meningkatkan ketanggapan terhadap dampak yang ditimbulkan oleh bencana tsunami, oleh karena itu, diperlukan standar operasi prosedur dan pemeriksaan rutin terhadap sistem dan rencana evakuasi (IOC \& UNESCO, 2012). Kegiatan kesiapsiagaan tsunami tetap perlu dilakukan walaupun telah dilakukannya tindakan mitigasi tsunami (BNPB, 2013), hal tersebut dikarenakan 1) efektivitas tindakan mitigasi baru akan terlihat saat ancaman tsunami benar-benar terjadi dan 2) walaupun sebuah kawasan telah siap dengan tindakan mitigasi, tidak seorang pun benar-benar mengetahui besaran (magnitude) dari ancaman tsunami yang akan terjadi. Rencana kesiapsiagaan lebih merupakan tindakan antisipatif jika suatu saat ancaman tsunami benar-benar terjadi. Rencana tersebut merefleksikan sikap kita yang siap terhadap ancaman tsunami yang akan terjadi, maupun sikap siaga bila ancaman tsunami menjadi kenyataan. Kesiapsiagaan bertujuan untuk membangun kapasitas yang diperlukan untuk secara efektif mampu mengelola segala macam keadaan darurat dan menjembatani masa transisi dari tanggap darurat ke pemulihan yang berkelanjutan.

Secara umum, hotel adalah salah satu industri pariwisata yang memiliki prosedur dan sistem operasi yang solid dan konsisten. Sebagian besar hotel telah membentuk sistem tanggap darurat mereka, terutama untuk bahaya kebakaran. Membangun kesiapsiagaan tsunami harus dimasukkan ke dalam prosedur yang ada, terutama di kawasan pariwisata yang rawan tsunami. Hotel siaga tsunami adalah hotel yang telah menetapkan prosedur, sistem operasi, dan langkah-langkah yang harus dilakukan dalam menghadapi tsunami, mulai dari tanggap darurat, evakuasi selama bencana, dan rencana pemulihan pasca bencana. Seluruh pemangku kepentingan (manajemen dan staf hotel) tahu bagaimana mempersiapkan diri, tanggap darurat, dan pulih dari bencana tsunami (IOC \& UNESCO, 2012). Begitu hotel mengetahui kondisi kerawanan tsunami yang ada di wilayahnya, hotel dapat mulai membangun kapasitas mereka untuk meningkatkan kesiapsiagaannya. Terdapat beberapa indikator penting yang perlu dibangun hotel sehubungan dengan upaya pengurangan risiko bencana tsunami pada aspek non-struktural (IOC \& UNESCO, 2012), mencakup: peta evakuasi, rambu-rambu tsunami, jalur evakuasi, sirene tsunami, titik kumpul tsunami, program edukasi tsunami, program kerja sama, dan program perlindungan.

Meskipun telah terdapat beberapa studi terdahulu yang membahas pentingnya upaya pengurangan risiko bencana bagi usaha hotel di kawasan rawan bencana berdasarkan perspektif aspek mitigasi, ketahanan, tanggap darurat, dan pemulihan, namun masih terbatasnya studi yang mengkaji akan pentingnya program kesiapsiagaan tsunami pada usaha hotel. Oleh karena itu, usaha hotel di kawasan pariwisata yang secara geografis sangat rawan tsunami memerlukan program kesiapsiagaan tsunami dalam menunjang keberlangsungan aktivitas wisata, keselamatan wisatawan, dan keberlanjutan industri pariwisata. Penelitian ini bertujuan untuk mengidentifikasi program kesiapsiagaan usaha hotel terhadap tsunami di kawasan pariwisata Anyer. Untuk mendukung tujuan tersebut, diidentifikasi juga program atau kebijakan yang telah ditetapkan oleh pemerintah daerah Provinsi Banten dan Kabupaten Serang.

\section{Metodologi}

Pendekatan yang digunakan pada penelitian ini adalah penelitian kualitatif yang bertujuan untuk mengeksplorasi dan memahami program kesiapsiagaan tsunami yang dilakukan oleh usaha hotel di kawasan pariwisata Anyer. Penelitian ini dilakukan selama enam bulan yang dimulai dari 
bulan Juli hingga November 2020 dan dilakukan pada delapan usaha hotel di kawasan pariwisata Anyer yang mencakup Resort Prima Anyer, Hawaii Resort Family Suites, Villa Pondok Club Bahari, Wisma Kompas Gramedia, Vila Karang Sono, Marbella Hotel Convention and Spa, My Pisita Anyer Resort, dan Allisan Resort Anyer.

Pada penelitian ini menggunakan data primer dan sekunder yang terdapat kaitannya dengan kesiapsiagaan bencana dan pengurangan risiko tsunami, serta arahan kebijakan penanggulangan bencana di kawasan pariwisata Anyer. Pengumpulan data primer bertujuan untuk mengumpukan data dan informasi yang ditujukan untuk mendapatkan gambaran umum secara objektif terhadap kondisi eksisting dan arahan kebijakan penanggulangan kebencanaan di wilayah penelitian. Metode pengumpulan data dilakukan melalui observasi dan wawancara kepada dua operasional manager, dua general manager, dan empat hotel manager di kawasan pariwisata Anyer (Tabel 1). Dilakukan pula wawancara terkait program kesiapsiagaan usaha hotel. Pengumpulan data sekunder dilakukan melalui desk study yang bertujuan untuk mendapatkan data dan informasi dari berbagai dokumen kebijakan, pustaka, dan penelitian terdahulu terkait kesiapsiagaan usaha hotel dan pengurangan risiko bencana.

Tabel 1. Narasumber pada usaha hotel di kawasan pariwisata Anyer

\begin{tabular}{cll}
\hline Narasumber & \multicolumn{1}{c}{ Jabatan } & \multicolumn{1}{c}{ Usaha hotel } \\
\hline 1 & Hotel Manager & Resort Prima Anyer \\
2 & Operasional Manager & Hawaii Resort Anyer \\
3 & General Manager & Villa Pondok Club Bahari \\
4 & Hotel Manager & Wisma Kompas \\
5 & Hotel Manager & Villa Karang Sono \\
6 & General Manager & Hotel Marbella Anyer \\
7 & Hotel Manager & My Pisita Anyer Resort \\
8 & Hotel Manager & Allisa Resort Hotel Anyer \\
\hline
\end{tabular}

Data yang telah didapatkan kemudian ditinjau kembali kebenarannya dengan tujuan untuk menghasilkan data yang valid dalam menunjang kredibilitas data sesuai hasil temuan empiris. Uji kredibilitas pada penelitian ini dilakukan dengan cara triangulasi melalui pemeriksaan ulang pada data hasil observasi, wawancara, dan studi literatur. Selain itu dilakukan juga diskusi dengan narasumber terhadap data yang diperoleh untuk memastikan kebenaran data.

Penelitian ini menggunakan metode analisis data kualitatif dengan tujuan untuk menganalisis upaya pengurangan risiko tsunami yang dilakukan oleh usaha hotel. Tahapan-tahapan analisis data pada penelitian ini dilakukan melalui tahapan analisis data sebelum di lapangan, reduksi data, penyajian data, dan penarikan kesimpulan.

\section{Hasil dan Pembahasan}

Kawasan pariwisata Anyer terletak di Pesisir Selat Sunda yang merupakan pantai barat Pulau Jawa. Secara administratif kawasan pariwisata Anyer terletak di Kecamatan Anyer, Kabupaten Serang. Nama Anyer berasal dari kata anyar dalam Bahasa Jawa dan Sunda yang artinya baru. Nama anyar saat ini masih digunakan sebagai nama Kecamatan dengan Anyer sebagai ibu kota kecamatannya. Sebelumnya, Anyer memiliki nama Sudi Mampir yang didirikan pada tahun 1666 oleh Kesultanan Banten. Setelah terjadinya letusan Gunung Krakatau pada tahun 1883, daerah Sudi Mampir sudah tidak berpenghuni karena dampak letusan. Seiring waktu, banyaknya orang berdatangan ke tempat tersebut, sehingga tempat itu dibangun kembali dan diberi nama anyar yang artinya tempat baru. 
Kawasan pariwisata Anyer memiliki potensi bencana yang relatif tinggi diantara kawasan pariwisata lainnya di Provinsi Banten. Lokasinya berdekatan dengan Gunung Anak Krakatau dan dilintasi oleh Cincin Api Pasifik, kawasan pariwisata Anyer menjadi rawan Tsunami. Tercatat dalam dua abad terakhir terdapat dua kali peristiwa tsunami di kawasan Selat Sunda yaitu pada tahun 1883 tahun 2018 (Paris et al., 2014; Wulung \& Abdullah, 2020). Kedua letusan tersebut mengakibatkan gelombang tsunami yang berdampak terhadap sosial dan ekonomi, terutama di kawasan pariwisata Anyer. Terjadinya bencana Tsunami Selat Sunda pada tanggal 22 Desember 2018 dipicu akibat pasang tinggi dan longsor bawah laut dari erupsi Gunung Anak Krakatau, bencana tersebut menyebabkan kerugian ekonomi dan menyebabkan efek domino berupa pembatalan kunjungan wisatawan hingga 10 persen, sebelum dilanda tsunami, tingkat hunian hotel dan penginapan di kawasan pariwisata Anyer mencapai 80-90 persen.

\subsection{Kebijakan Kepariwisataan dan Kebencanaan di Kawasan Pariwisata Anyer}

Program pemerintah setempat, yaitu Provinsi Banten dan Kabupaten Serang terkait kebencanaan dan kepariwisataan di kawasan pesisir Selat Sunda merupakan upaya mengurangi risiko bencana akibat tsunami. Terdapat enam arahan kebijakan Provinsi Banten terkait arahan penanggulangan bencana. Kebijakan pertama yaitu Peraturan Daerah Provinsi Banten Nomor 1 Tahun 2015 tentang Penyelenggaraan Penanggulangan Bencana yang memaparkan bahwa tanggung jawab Pemerintah Provinsi Banten dalam menyelenggarakan penanggulangan bencana memiliki wewenang dalam menetapkan, membuat, dan melaksanakan kebijakan penanggulangan bencana dan mengatur, merumuskan, dan mengendalikan penyelenggaraan penanggulangan bencana. Dalam peraturan ini dijelaskan juga hak masyarakat dalam mendapatkan pendidikan dan pelatihan tentang penanggulangan bencana diberikan kepada masyarakat untuk membangun kesiapsiagaan, keterampilan, dan kemandirian dalam menghadapi bencana. Selain itu masyarakat berkewajiban dalam 1) menjaga kehidupan sosial masyarakat yang harmonis, memelihara keseimbangan, keserasian, keselarasan, dan kelestarian fungsi lingkungan hidup; 2) berperan aktif dalam penanggulangan bencana; 3) memberikan informasi yang benar kepada publik tentang penanggulangan bencana; dan 4) memberikan informasi yang benar tentang data diri. Usaha hotel di Kawasan Anyer harus berperan aktif dalam penanggulangan bencana untuk membangun kesiapsiagaan bencana serta memberikan literasi dan informasi yang benar kepada masyarakat setempat dan wisatawan tentang penanggulangan bencana. Sebagian besar usaha hotel melaporkan program kesiapsiagaan bencana kepada pemerintah setempat sesuai dengan arahan kebijakan yang berlaku di daerah tersebut (AlBattat \& MatSom, 2014). Hal tersebut dilakukan untuk mengurangi risiko dan dampak yang diakibatkan oleh tsunami terhadap masyarakat, wisatawan, dan manajemen usaha hotel yang berada di kawasan pariwisata Anyer yang rawan bencana.

Pada arahan kebijakan yang kedua, yaitu Peraturan Daerah Provinsi Banten 3 Tahun 2010 tentang Badan Penanggulangan Bencana Daerah memaparkan mengenai pembentukan, kedudukan, tugas, dan fungsi dari Badan Penanggulangan Bencana Daerah (BPBD) Provinsi Banten. Secara kedudukan, BPBD Provinsi Banten merupakan satuan kerja perangkat daerah sebagai lembaga lain di lingkungan Pemerintah Daerah yang berada di bawah dan bertanggungjawab kepada Gubernur. BPBD Provinsi Banten dalam pelaksanaan tugasnya memiliki fungsi 1) perumusan dan penetapan kebijakan penanggulangan bencana dan penanganan pengungsi dengan bertindak cepat dan tepat, efektif dan efisien; dan 2) pengoordinasian pelaksanaan kegiatan penanggulangan bencana secara terencana dan terpadu serta menyeluruh. Sesuai arahan kebijakan ini, usaha hotel di kawasan pariwisata Anyar sebaiknya melakukan koordinasi dengan BPBD Provinsi Banten dalam upaya program kesiapsiagaan tsunami, baik itu dalam perencanaan, pengelolaan, hingga pelatihan bagi manajemen dan wisatawan. Diperlukan 
integrasi yang baik antara usaha hotel dengan BPBD dalam program penanggulangan bencana di kawasan pesisir sebagai upaya membangun ketahanan bencana struktural dan non-struktural (Wahyuningtyas et al., 2020).

Pada arahan kebijakan yang ketiga, dijelaskan bahwa kawasan bencana alam di Provinsi Banten meliputi kawasan rawan bencana letusan gunung api, banjir, tsunami, dan gerakan tanah. Peraturan Daerah Provinsi Banten Nomor 2 Tahun 2011 tentang Rencana Tata Ruang Wilayah (RTRW) Provinsi Banten, mengatur arahan zonasi untuk kawasan rawan bencana alam, diantaranya terkait penyelenggaraan tanggul penahan, terasering, jalur mitigasi atau evakuasi, sistem informasi bencana, sistem peringatan dini, standar operasi dan prosedur bencana di kawasan rawan bencana. Sesuai arahan kebijakan tersebut, usaha hotel di kawasan pariwisata Anyer diwajibkan untuk memiliki sistem informasi bencana yang diperuntukkan bagi wisatawan yang menginap serta para karyawan hotel. Selain itu, jalur evakuasi serta standar dan prosedur bencana wajib diimplementasikan bagi usaha hotel di kawasan pariwisata Anyer yang bertujuan supaya dapat mengurangi risiko tsunami. Pentingnya mengikuti arahan pemerintah setempat yang akan membuat ketahanan pada usaha hotel, selain itu prosedur bencana internal yang dibuat oleh usaha hotel mampu meningkatkan keselamatan wisatawan dan para karyawan hotel (Ivkov et al., 2019).

Pada Peraturan Daerah Provinsi Banten Nomor 6 Tahun 2019 tentang Rencana Induk Pembangunan Kepariwisataan Provinsi (Ripparprov) Banten Tahun 2018-2025, kawasan pariwisata Anyer masuk dalam Kawasan Strategis Pariwisata Provinsi Anyer - Cinangka dan sekitarnya. Dalam peraturan ini, memberikan arahan pembangunan kepariwisataan dilaksanakan berdasarkan tata kelola yang baik secara lintas sektor, lintas daerah, dan lintas pelaku dalam mewujudkan pembangunan kepariwisataan yang berkelanjutan. Hal tersebut mengindikasikan bahwa penanggulangan bencana di kawasan pariwisata Anyer harus dilaksanakan dengan tata kelola baik dengan melibatkan pemangku kepentingan terkait yang mencakup pemerintah daerah, industri pariwisata, dan masyarakat setempat dalam menciptakan kawasan pariwisata Anyer yang berkelanjutan. Menciptakan kemitraan antara organisasi pemerintah, publik dan sektor swasta untuk menanggulangi bencana alam pada usaha hotel akan berkontribusi untuk pengelolaan kebencanaan yang berkelanjutan (Ivkov et al., 2019). Selain itu, ditetapkan juga bagi industri pariwisata diwajibkan memiliki fasilitas keamanan seperti alat pemadam kebakaran dan fasilitas tanggap darurat (early warning system).

Arahan pada kebijakan selanjutnya yaitu Peraturan Daerah Provinsi Banten Nomor 3 Tahun 2018 tentang Perlindungan dan Pemberdayaan Masyarakat Pesisir. Dokumen kebijakan ini Pemerintah Daerah Provinsi Banten melaksanakan perlindungan dan pemberdayaan masyarakat pesisir dan pulau-pulau kecil untuk melindungi kegiatan usaha, memberikan nilai lebih, dan nilai tambah. Sasaran perlindungan dan pemberdayaan masyarakat pesisir dan pulau-pulau kecil meliputi nelayan, pembudidaya air payau, masyarakat pesisir, usaha perikanan, kelompok usaha bersama, pedagang, dan pelaku usaha kecil. Dalam upaya perlindungan, Pemerintah Daerah Provinsi Banten wajib memuat upaya adaptasi dan mitigasi bencana dampak perubahan iklim yang dilaksanakan dengan memperhatikan unsur sosial, ekonomi, dan budaya masyarakat, serta kelestarian lingkungan hidup. Usaha hotel di kawasan pariwisata Anyer, selain memberikan peluang lapangan pekerjaan bagi masyarakat setempat, juga berkewajiban untuk memberikan perlindungan dan pemberdayaan masyarakat setempat melalui berbagai program sosialnya. Usaha hotel harus memiliki komitmen dalam program sosial terhadap masyarakat setempat baik itu pra dan pasca bencana (Henderson, 2007)

Arahan kebijakan yang terakhir, yaitu Peraturan Gubernur Banten Nomor 1 Tahun 2013 tentang Standar Biaya Umum Dana Siap Pakai Status Keadaan Darurat Penanganan Bencana. Pada arahan kebijakan ini yang dimaksud dengan status keadaan darurat adalah suatu keadaan yang 
ditetapkan oleh Pemerintah untuk jangka waktu tertentu atas dasar rekomendasi Badan yang diberi tugas untuk menanggulangi bencana. Status Keadaan Darurat dimulai sejak Status Siaga Darurat, Tanggap Darurat dan transisi dari Darurat ke pemulihan. Sementara dana siap pakai adalah dana yang selalu tersedia dan dicadangkan oleh Pemerintah untuk digunakan pada saat tanggap darurat bencana sampai batas waktu tanggap darurat berakhir. Dokumen kebijakan ini bertujuan untuk percepatan penanganan dalam Penanggulangan Bencana Daerah. Dana siap pakai dapat diberikan kepada daerah yang terkena bencana dalam bentuk 1) uang, cek, dan giro; 2) peralatan dan logistik; 3) bantuan transportasi (darat, air, dan udara); dan 4) bantuan sumber daya manusia (jasa). Pasca tsunami tahun 2018, usaha hotel di kawasan pariwisata Anyer tetap memperhatikan arahan pemerintah provinsi dan daerah terkait operasional usahanya. Hal tersebut mengindikasikan bahwa peraturan ini dibuat sebagai panduan bagi usaha hotel ketika bencana terjadi hingga waktu tanggap darurat dinyatakan berakhir. Pariwisata akan runtuh tanpa dukungan finansial ketika terjadi bencana, dalam hal ini, pemerintah memainkan peran penting dalam hal pinjaman paket keuangan langsung untuk mendukung pemulihan (Rindrasih et al., 2019). Baik itu pemerintah, pemerintah Provinsi, dan pemerintah daerah telah menetapkan berbagai kebijakan penanggulangan kebencanaan sebagai upaya pengurangan risiko bencana di kawasan rawan bencana, hal tersebut selain menjadi panduan bagi masyarakat juga dapat dipergunakan sebagai panduan bagi usaha hotel dalam mengambangkan usaha hotel siaga bencana (Wulung \& Abdullah, 2020).

Pada skala pemerintah daerah Kabupaten Serang, penetapan kebijakan terkait penanggulangan bencana di kawasan pariwisata Anyer mencakup 1) Peraturan Daerah Kabupaten Serang Nomor 10 Tahun 2011 tentang Rencana Tata Ruang Wilayah (RTRW) Kabupaten Serang Tahun 2011-2031; 2) Peraturan Daerah Kabupaten Pandeglang Nomor 8 Tahun 2014 tentang Rencana Induk Pembangunan Kepariwisataan Kabupaten Serang Tahun 2014-2025; dan 3) Peraturan Daerah Kabupaten Pandeglang Nomor 4 Tahun 2014 tentang Penanggulangan Bencana di Kabupaten Serang. Segala pengelolaan kawasan pariwisata di kawasan Anyer harus mengacu pada kebijakan penanggulangan bencana yang telah diatur dan ditetapkan baik itu oleh pemerintah daerah Provinsi Banten dan Kabupaten Serang.

Arahan kebijakan pertama telah ditetapkan kebijakan terkait kepariwisataan dan kebencanaan yaitu pengembangan pariwisata berkelanjutan bertumpu budaya lokal dan pengembangan sistem penanggulangan bencana pada kawasan rawan bencana. Pengembangan sistem penanggulangan bencana pada kawasan rawan bencana di Kabupaten Serang dilakukan dengan strategi, diantaranya yaitu mengembangkan struktur fisik dan non fisik yang berdampak langsung dalam pengurangan risiko bencana serta mengembangkan jalur dan ruang evakuasi bencana. Kebijakan ini telah menetapkan jalur dan ruang evakuasi bencana di kawasan pariwisata Anyer yang terdiri dari 1) jalur evakuasi tsunami yang berawal dari Kecamatan Anyar - Kecamatan Mancak - Kecamatan Gunung Sari; 2) ruang evakuasi bencana tsunami yang ditetapkan di lapangan olahraga setempat, bangunan pemerintah setempat, dan ruang terbuka publik setempat. Usaha hotel di kawasan pariwisata Anyer telah didukung oleh kebijakan ini terkait tata ruang kebencanaan yang mencakup arahan jalur evakuasi ruang evakuasi. Selain itu telah ditetapkan juga pengembangan sistem penanggulangan bencana fisik maupun non-fisik pada kawasan pariwisata Anyer sebagai upaya pengurangan risiko bencana.

Kebijakan kedua menetapkan kawasan pariwisata Anyer sebagai Kawasan Strategis Pariwisata Daerah (KPSD) Pantai Barat Anyer Cinangka di Destinasi Pariwisata Daerah (DPD) Serang Barat Utara. Ditetapkannya kawasan ini sebagai KPSD karena keterkaitannya dengan kawasan rawan bencana sesuai yang ditetapkan oleh perundang-undangan. Sementara pada arahan kebijakan terakhir menetapkan bahwa penyelenggaraan penanggulangan bencana di Kabupaten Serang terdiri atas 3 (tiga) tahap, meliputi pra bencana, saat tanggap darurat, dan pasca bencana. 
Selain itu, kebijakan ini telah menetapkan bahwa bagi lembaga usaha berhak mendapatkan kesempatan dalam penyelenggaraan penanggulangan bencana di daerah, baik secara tersendiri maupun bersama pihak lain. Pelaksanaan penyelenggaraan penanggulangan bencana di daerah oleh lembaga usaha harus menyesuaikan dengan kebijakan Pemerintah Daerah dengan tetap mengindahkan prinsip penanggulangan bencana dan berkoordinasi dengan BPBD. Sesuai arahan kebijakan tersebut, kawasan pariwisata Anyer merupakan kawasan pariwisata strategis dalam menunjang keberlangsungan pembangunan Kabupaten Serang. Selain itu, usaha hotel di kawasan pariwisata Anyer diperbolehkan untuk melaksanakan pengelolaan penanggulangan bencana secara independen dengan tetap memperhatikan prinsip penanggulangan bencana dan berkoordinasi dengan BPBD Kabupaten Serang.

\subsection{Upaya Kesiapsiagaan Tsunami Usaha Hotel}

Program kesiapsiagaan tsunami pada usaha hotel sebagai upaya mewujudkan hotel siaga tsunami di kawasan pariwisata Anyer ditinjau berdasarkan kesiapsiagaan non struktural sebelum terjadinya Tsunami Selat Sunda di penghujung tahun 2018. Program-program tersebut mencakup peta evakuasi, rambu-rambu tsunami, jalur evakuasi, sirene tsunami, titik kumpul tsunami, program edukasi tsunami, program kerja sama, dan program perlindungan. Identifikasi masingmasing program pada delapan usaha hotel di kawasan pariwisata Anyer dapat dilihat pada Tabel 2.

Tabel 2. Kesiapsiagaan non-struktural pada usaha hotel di kawasan pariwisata Anyer

\begin{tabular}{|c|c|c|c|c|c|c|c|c|}
\hline \multirow[b]{2}{*}{ Usaha hotel } & \multicolumn{8}{|c|}{ Kesiapsiagaan Non-Struktural } \\
\hline & $\begin{array}{c}\text { Peta } \\
\text { evakuasi }\end{array}$ & $\begin{array}{c}\text { Rambu- } \\
\text { rambu } \\
\text { tsunami }\end{array}$ & $\begin{array}{c}\text { Jalur } \\
\text { evakuasi }\end{array}$ & $\begin{array}{c}\text { Sirene } \\
\text { tsunami }\end{array}$ & $\begin{array}{c}\text { Titik } \\
\text { kumpul } \\
\text { tsunami }\end{array}$ & $\begin{array}{c}\text { Program } \\
\text { edukasi } \\
\text { tsunami }\end{array}$ & $\begin{array}{c}\text { Program } \\
\text { kerja } \\
\text { sama }\end{array}$ & $\begin{array}{c}\text { Program } \\
\text { perlindungan }\end{array}$ \\
\hline Resort Prima Anyer & - & - & - & - & $\mathrm{V}$ & - & - & $\mathrm{V}$ \\
\hline Hawaii Resort Anyer & V & $\mathrm{V}$ & $\mathrm{V}$ & $\mathrm{V}$ & - & - & $\mathrm{V}$ & $\mathrm{V}$ \\
\hline $\begin{array}{l}\text { Villa Pondok Club } \\
\text { Bahari }\end{array}$ & - & - & - & - & V & - & - & - \\
\hline Wisma Kompas & - & - & - & - & V & V & - & $\mathrm{V}$ \\
\hline Villa Karang Sono & - & - & - & - & V & - & - & - \\
\hline $\begin{array}{l}\text { Hotel Marbella } \\
\text { Anyer }\end{array}$ & $\mathrm{V}$ & $\mathrm{V}$ & $\mathrm{V}$ & - & V & $\mathrm{V}$ & - & $\mathrm{V}$ \\
\hline $\begin{array}{l}\text { My Pisita Anyer } \\
\text { Resort }\end{array}$ & - & - & - & - & V & - & - & - \\
\hline $\begin{array}{l}\text { Allisa Resort Hotel } \\
\text { Anyer }\end{array}$ & $\mathrm{V}$ & $\mathrm{V}$ & $\mathrm{V}$ & $\mathrm{V}$ & V & $\mathrm{V}$ & - & - \\
\hline
\end{tabular}

Peta evakuasi yang terpasang di setiap kamar hotel masih belum disediakan oleh Wisma Kompas, Resort Prima Anyer, My Pisita Hotel Anyer, Villa Pondok Club Bahari, dan Villa Karang Sono. Dari hasil penelitian yang dilakukan, peta evakuasi tsunami yang terpasang di setiap kamar hotel hanya ada di Hawaii Resort Anyer, Allisa Resort Hotel Anyer, dan Hotel Marbella Anyer. Secara keseluruhan dari hasil penelitian ini menunjukkan bahwa hanya terdapat tiga dari delapan hotel yang sudah memasang peta evakuasi tsunami di setiap kamar hotel. Sedangkan untuk ketersediaan rambu-rambu evakuasi tsunami di kawasan hotel masih belum semuanya menyediakan dikarenakan dari hasil penelitian yang dilakukan hanya terdapat 3 hotel yang sudah menyediakan rambu - rambu evakuasi tsunami di kawasan hotel yaitu Hawaii Resort Anyer, Allisa Resort Hotel Anyer, dan Hotel Marbella Anyer. Sedangkan tiga hotel lainnya belum menyediakan rambu - rambu evakuasi tsunami di kawasan hotelnya. Informasi mengenai peta evakuasi tsunami dan rambu-rambu tsunami di usaha hotel memiliki peran penting sebagai panduan bagi wisatawan 
Informasi mengenai peta evakuasi tsunami di usaha hotel memiliki peran penting sebagai panduan bagi wisatawan yang menginap. Peta evakuasi yang memuat jalur evakuasi, rambu petunjuk arah evakuasi, dan prosedur-prosedur yang harus dilakukan oleh wisatawan ketika terdengar sirene tsunami atau terjadi tsunami. Fasilitas peta evakuasi dan rambu penunjuk arah evakuasi sangat penting untuk efektivitas dan pengawasan tindakan penyelamatan saat terjadi bencana (Wahyuningtyas et al., 2020). Peta evakuasi dan rambu-rambunya harus jelas mengidentifikasikan arah menuju titik kumpul evakuasi dan diproduksi dalam multibahasa, mengingat wisatawan yang menginap berasal dari berbagai daerah (Nguyen et al., 2016). Selain itu, jalur dan rambu-rambu evakuasi harus mengarah kepada jalur evakuasi tsunami yang telah ditetapkan oleh pemerintah Kabupaten Serang sesuai dengan arahan kebijakan pada dokumen RTRW Kabupaten Serang Tahun 2011-2031 yaitu yang berawal dari hotel di Kecamatan Anyer dan berakhir di Kecamatan Gunung Sari.

Peta dan rambu-rambu evakuasi merupakan bagian dari perencanaan evakuasi dalam kerangka kerja pengurangan risiko bencana pada usaha hotel (Brown et al., 2017; IOC \& UNESCO, 2012; Ivkov et al., 2019). Terdapat indikator lainnya yang menjadi bagian perencanaan evakuasi bencana pada usaha hotel, yaitu tangga dan pintu darurat serta titik kumpul evakuasi tsunami. Usaha hotel di kawasan pariwisata Anyer telah menyediakan tangga dan pintu darurat di setiap unit bangunan hotel hanya terdapat pada tiga hotel yaitu Hawaii Resort Anyer, Allisa Resort Hotel Anyer, dan Hotel Marbella Anyer. Sedangkan lima hotel lainnya belum menyediakan tangga dan pintu di setiap bangunan hotel. Sementara itu, ketersediaan area untuk titik kumpul ketika terjadi tsunami sudah disediakan oleh seluruh usaha hotel, mencakup Wisma Kompas, Resort Prima Anyer, Allisa Resort Hotel, My Pisita Anyer Resort, Villa Pondok Club Bahari, Villa Karang Sono, dan Hotel Marbella Anyer. Secara keseluruhan, usaha hotel di kawasan pariwisata Anyer telah menyediakan area sebagai titik kumpul ketika terjadi bencana alam tsunami meskipun beberapa usaha hotel belum memiliki tangga dan pintu darurat dikarenakan usaha hotel tersebut diklasifikasikan sebagai vila dan resor yang cenderung terpisah tidak dalam satu bangunan atau terpisah dari satu kamar dengan kamar lainnya. Bencana alam secara tidak langsung memaksa evakuasi masal masyarakat dan wisatawan di kawasan pariwisata (Becken \& Hughey, 2013). Masyarakat setempat di kawasan pariwisata memiliki pengetahuan lebih baik tentang risiko bahaya serta rencana dan strategi evakuasi dibandingkan dengan wisatawan, di sinilah peran usaha hotel untuk mengedukasi dan memandu wisatawan sebagai upaya kesiapsiagaan bencana (AlBattat \& MatSom, 2014; Nguyen et al., 2016). Ketergantungan wisatawan pada usaha hotel sangat terjadi tsunami menjadi hal yang harus diantisipasi oleh pengelola hotel dalam menciptakan keamanan dan keselamatan wisatawan (AlBattat \& MatSom, 2013, 2019). Perencanaan evakuasi beserta sistem informasi bencana di usaha hotel menjadi bagian penting dalam program kesiapsiagaan tsunami, hal tersebut sesuai dengan arahan kebijakan penanggulangan bencana Provinsi Banten yang mewajibkan usaha hotel memiliki sistem informasi bencana dalam menunjang keselamatan wisatawan. Sementara pada kebijakan penanggulangan bencana Kabupaten Serang telah memberikan arahan untuk ruang evakuasi bencana tsunami di kawasan pariwisata Anyer yang di tetapkan di lapangan olahraga setempat, bangunan pemerintah setempat, dan ruang terbuka publik setempat. Hal tersebut mengindikasikan bahwa usaha hotel di kawasan pariwisata Anyer harus menganalisis ruang evakuasi bencana tsunami terdekat, aman, dan tepat bagi wisatawan.

Mekanisme pemberitahuan bencana tsunami yang berupa sirene masih sangat minim diterapkan oleh setiap hotel. Hal ini terbukti dengan hanya sedikit hotel yang sudah memiliki mekanisme tersebut. hotel yang sudah menerapkan mekanisme tersebut terdiri dari Hawaii Resort Anyer, dan Allisa Resort Hotel Anyer. Sedangkan di enam hotel lainnya, mekanisme ini belum diterapkan. Sirene tsunami memiliki fungsi penting sebagai tanda peringatan bagi wisatawan yang 
berada di hotel dan masyarakat setempat. Keterbatasan sirene tsunami pada usaha hotel berkontribusi pada hilangnya nyawa wisatawan di destinasi pariwisata (Calgaro \& Lloyd, 2008). Pengelola hotel wajib memberikan informasi dan edukasi kepada wisatawan tentang sirene tsunami, hal tersebut sebagai antisipasi jika terjadi kepanikan yang dialami wisatawan ketika sirene tsunami aktif (Becken \& Hughey, 2013; IOC \& UNESCO, 2012). Penyelenggaraan sistem peringatan dini atau sirene tsunami telah ditetapkan dalam RTRW Provinsi Banten untuk diimplementasikan pada kawasan rawan bencana. Usaha hotel di wilayah pariwisata Anyer dapat berkoordinasi dengan BPBD Provinsi Banten dan BPBD Kabupaten Serang terkait penyelenggaraan sistem peringatan dini tsunami. Hal tersebut dapat diinisiasi dengan penandatanganan nota kesepakatan atau Memorandum of Understanding (MoU) antara pihak usaha hotel di kawasan pariwisata Anyer dengan pemerintah pada skala Kabupaten Serang, Provinsi Banten, dan Nasional, seperti BPBD/ BNPB, Dinas Pariwisata, Palang Merah Indonesia, Balawista dan lembaga pemerintah lainnya yang membawahi urusan kebencanaan dan kepariwisataan. Dari hasil observasi dan wawancara yang dilakukan terhadap delapan hotel yang berada di kawasan pariwisata Anyer, hanya terdapat satu hotel yang telah memiliki MOU dengan instansi penanggulangan bencana dalam rangka meningkatkan fasilitas kebencanaan dan kapasitas para karyawan hotel terhadap upaya pengurangan risiko tsunami, yaitu Hawaii Resort Anyer. Usaha hotel membutuhkan kolaborasi dengan pemerintah dalam penyelenggaraan bencana struktural dan non struktural dalam mencapai manajemen bencana berkelanjutan (Nguyen et al., 2016).

Sebagian hotel yang ada di kawasan pariwisata Anyer sudah memiliki program edukasi berhubungan dengan tsunami dan melibatkan seluruh manajemen dan karyawan hotel. Selain itu, hotel-hotel sebagian besar usaha hotel belum memiliki kebijakan perlindungan terhadap karyawan hotel serta aset usahanya. Pendidikan dan pelatihan sebagai upaya pengurangan risiko menjadi bagian dari kebijakan usaha hotel yang dapat menunjang kesiapsiagaan bencana bagi para karyawannya (Kimura et al., 2014; Rindrasih et al., 2019; Tsai et al., 2020). Pendidikan dan pelatihan evakuasi bencana merupakan bagian dari kesiapsiagaan non struktural dapat menjadi solusi alternatif yang dalam mencegah hilangnya nyawa, memperkuat ketahanan bencana, dan mampu mengurangi dampak kerugian material akibat bencana (Holmes, 2016; Nguyen et al., 2016). Kehadiran karyawan usaha hotel memiliki nilai berharga bagi keberlangsungan operasional hotel dan mampu membangun ketahanan bencana yang terintegrasi antar karyawan dan wisatawan, oleh karena itu usaha hotel wajib memberikan kebijakan yang dikeluarkan untuk melindungi hakhak karyawan baik itu sebelum, selama, dan setelah bencana (Brown et al., 2019). Di sisi lain, pengelola hotel harus cermat dalam memilih karyawan mana yang akan mendapatkan hak dan mampu mewariskan ilmu pengetahuan bencana kepada karyawan baru, hal tersebut dikarenakan tingginya tingkat pergantian karyawan pada usaha hotel (Nguyen et al., 2018). Keselamatan dan keamanan para karyawan hotel juga termuat dalam kebijakan penyelenggaraan bencana Kabupaten Serang yang mengarahkan bahwa bagi lembaga usaha di Kabupaten Serang dapat merancang kebijakan penanggulangan bencananya secara independen dengan tetap memperhatikan aturan dan arahan yang telah ditetapkan.

Penelitian terdahulu telah menerapkan upaya pengurangan risiko tsunami pada usaha hotel melalui aspek mitigasi, ketahanan, dan tanggap darurat. Penelitian ini difokuskan kepada kesiapsiagaan usaha hotel dalam upaya mengurangi risiko tsunami di kawasan pariwisata, sehingga diharapkan mampu berkontribusi pada manajemen bencana bagi usaha hotel di kawasan rawan tsunami, khususnya terkait program kesiapsiagaannya. Meskipun sebagian besar usaha hotel di kawasan pariwisata Anyer belum sepenuhnya menerapkan program kesiapsiagaan tsunami, secara tidak langsung dengan dilakukannya penelitian ini diharapkan mampu berkontribusi dalam 
mempersiapkan program kesiapsiagaan tsunami bagi usaha hotel yang berada di kawasan pesisir Selat Sunda dan usaha hotel lainnya yang berada di kawasan rawan tsunami di Indonesia dan internasional dalam menunjang terwujudnya hotel siaga tsunami.

\section{Kesimpulan}

Tsunami Selat Sunda di penghujung tahun 2018 memicu hotel-hotel di destinasi pesisir untuk mengembangkan dan menerapkan konsep hotel siaga tsunami. Tidak adanya prosedur operasional standar tsunami merupakan salah satu penyebab terbesar banyaknya korban jiwa. Upaya kesiapsiagaan tsunami bertujuan untuk memberikan keselamatan dan keamanan bagi wisatawan dan karyawan hotel, yang pada akhirnya dapat memberikan kelangsungan usaha hotel kawasan pariwisata Anyer. Usaha hotel di kawasan pariwisata Anyer cenderung belum sepenuhnya menerapkan program non struktural kesiapsiagaan tsunami.

\section{Saran}

Penelitian ini fokus pada program kesiapsiagaan tsunami non struktural usaha hotel di kawasan pariwisata Anyer. Penelitian lebih lanjut dapat diarahkan pada aspek struktural dari kesiapsiagaan tsunami atau pada tahapan pengurangan risiko bencana lainnya seperti tanggap darurat dan pemulihan bencana. Selain itu, penelitian lebih lanjut dapat dilakukan pada usaha hotel yang terletak di kawasan rawan bencana gempa bumi, banjir, dan bencana alam lainnya. Tidak menutup kemungkinan untuk melakukan penelitian lebih lanjut mengenai kesiapsiagaan usaha hotel terhadap bencana non alam dan bencana sosial seperti kondisi usaha hotel dalam menghadapi teror atau pada masa new normal pandemi Covid-19.

\section{Ucapan Terima Kasih}

Penulis mengucapkan terima kasih kepada Universitas Pendidikan Indonesia yang telah memberi dukungan finansial pada penelitian ini.

\section{Daftar Pustaka}

AlBattat, A. R., \& MatSom, A. P. (2013). Emergency Preparedness for Disasters and Crises in the Hotel Industry. SAGE Open, 3(3), 215824401350560. https://doi.org/10.1177/2158244013505604

AlBattat, A. R., \& MatSom, A. P. (2014). Emergency Planning and Disaster Recovery in Malaysian Hospitality Industry. Procedia - Social and Behavioral Sciences, 144, 45-53. https://doi.org/10.1016/j.sbspro.2014.07.272

AlBattat, A. R., \& MatSom, A. P. (2019). Disaster Planning and Preparedness in the Hotel Industry. Emerald.

Aprilia, K., \& Stiv, Y. (2018). Gempa dan Tsunami di Palu. Jurnal EDimensi Arsitektur, 7(1), 1033-1040.

Becken, S., \& Hughey, K. F. D. (2013). Linking tourism into emergency management structures to enhance disaster risk reduction. Tourism Management, 36, 77-85. https://doi.org/10.1016/j.tourman.2012.11.006

BNPB. (2013). Indeks Risiko Bencana Indonesia. Direktorat Pengurangan Risiko Bencana, Deputi Bidang Pencegahan dan Kesiapsiagaan.

Brown, N. A., Rovins, J. E., Feldmann-Jensen, S., Orchiston, C., \& Johnston, D. (2017). Exploring disaster resilience within the hotel sector: A systematic review of literature. International Journal of Disaster Risk Reduction, 22, 362-370. https://doi.org/10.1016/j.ijdrr.2017.02.005

Brown, N. A., Rovins, J. E., Feldmann-Jensen, S., Orchiston, C., \& Johnston, D. (2019). Measuring 
disaster resilience within the hotel sector: An exploratory survey of Wellington and Hawke's Bay, New Zealand hotel staff and managers. International Journal of Disaster Risk Reduction, 33, 108-121. https://doi.org/10.1016/j.ijdrr.2018.09.014

Cahyadi, F. D. (2019). Sejarah Tsunami di Selat Sunda Sebagai Dasar Pembangunan Wilayah Pesisir Banten. https://doi.org/10.31227/osf.io/jnfmw

Calgaro, E., \& Lloyd, K. (2008). Sun, sea, sand and tsunami: Examining disaster vulnerability in the tourism community of Khao Lak, Thailand. Singapore Journal of Tropical Geography, 29(3), 288-306. https://doi.org/10.1111/j.1467-9493.2008.00335.x

Darwati, D., Samad, M. A., \& Wekke, I. S. (2019). Collaborative Governance Dalam Pengelolaan Integrated Community Shelter Pasca Bencana di Kota Palu. https://doi.org/10.31227/osf.io/7kjte

Enz, C. A., \& Taylor, M. S. (2002). The safety and security of U.S. hotels: A post-September-11 report. Cornell Hotel and Restaurant Administration Quarterly, 43(5), 119-136. https://doi.org/10.1016/S0010-8804(02)80062-3

Faulkner, B. (2001). Towards a framework for tourism disaster management. In Managing tourist health and safety in the new millennium (Vol. 22, Issue 2, pp. 175-196). Routledge. https://doi.org/10.1016/S0261-5177(00)00048-0

Faulkner, B., \& Vikulov, S. (2001). Katherine, washed out one day, back on track the next: a postmortem of a tourism disaster. Tourism Management, 22(4), 331-344. https://doi.org/10.1016/S0261-5177(00)00069-8

Henderson, J. C. (2007). Corporate social responsibility and tourism: Hotel companies in Phuket, Thailand, after the Indian Ocean tsunami. International Journal of Hospitality Management, 26(1), 228-239. https://doi.org/10.1016/j.ijhm.2006.02.001

Holmes, T. (2016). Planning for Community Resilience: A Handbook for Reducing Vulnerability to Disasters, by Jamie Hicks Masterson, Walter Gillis Peacock, Shannon S. Van Zandt, Himanshu Grover, Lori Feild Schwarz, and John T. Cooper, Jr. . Journal of the American Planning Association, 82(2), 214-215. https://doi.org/10.1080/01944363.2016.1145012

IOC, \& UNESCO. (2012). A Guide to Tsunamis for Hotels. Intergovernmental Oceanographic Commission of UNESCO. http://neamtic.ioc-unesco.org

Ivkov, M., Blešić, I., Janićević, S., Kovačić, S., Miljković, D., Lukić, T., \& Sakulski, D. (2019). Natural Disasters vs Hotel Industry Resilience: An Exploratory Study among Hotel Managers from Europe. Open Geosciences, 11(1), 378-390. https://doi.org/10.1515/geo-2019-0030

Kimura, R., Hayashi, H., Suzuki, S., Kobayashi, K., Urabe, K., Inoue, S., \& Nishino, T. (2014). Systematization and sharing of disaster management literacy by DMLH. Journal of Disaster Research. https://doi.org/10.20965/jdr.2014.p0176

Maryanti, S., Netrawati, I. O., \& Faezal, F. (2019). Menggerakan Perekonomian Melalui Pemulihan Usaha dan Industri Mikro Kecil Menengah Pasca Bencana Gempa Bumi di Nusa Tenggara Barat. Media Bina Ilmiah, 14(4), 2321-2336.

Nguyen, D., Imamura, F., \& Iuchi, K. (2016). Disaster management in coastal tourism destinations: The case for transactive planning and social learning. International Review for Spatial Planning and Sustainable Development, 4(2), 3-17. https://doi.org/10.14246/irspsd.4.2_3

Nguyen, D. N., Imamura, F., \& Iuchi, K. (2018). Barriers towards hotel disaster preparedness: Case studies of post 2011 Tsunami, Japan. International Journal of Disaster Risk Reduction, 28, 585-594. https://doi.org/10.1016/j.ijdrr.2018.01.008

Paris, R., Wassmer, P., Lavigne, F., Belousov, A., Belousova, M., Iskandarsyah, Y., Benbakkar, M., Ontowirjo, B., \& Mazzoni, N. (2014). Coupling eruption and tsunami records: The Krakatau 1883 case study, Indonesia. Bulletin of Volcanology, 76(4), 1-23. 
https://doi.org/10.1007/s00445-014-0814-x

Reisinger, Y., \& Mavondo, F. (2005). Travel Anxiety and Intentions to Travel Internationally: Implications of Travel Risk Perception. Journal of Travel Research, 43(3), 212-225. https://doi.org/10.1177/0047287504272017

Rindrasih, E., Witte, P., Spit, T., \& Zoomers, A. (2019). Tourism and Disasters: Impact of Disaster Events on Tourism Development in Indonesia 1998-2016 and Structural Approach Policy Responses. Journal of Service Science and Management, 12(02), 93-115. https://doi.org/10.4236/jssm.2019.122006

Ritchie, B. W., Bentley, G., Koruth, T., \& Wang, J. (2011). Proactive crisis planning: Lessons for the accommodation industry. Scandinavian Journal of Hospitality and Tourism, 11(3), 367386. https://doi.org/10.1080/15022250.2011.600591

Shalih, O. (2019). Membangun Ketahanan (Resiliensi) Bencana Pada Kawasan Pariwisata (Studi Kasus: Kabupaten Pandeglang Pasca Tsunami Selat Sunda 2018). https://doi.org/10.31227/osf.io/v3yxs

Tsai, C. H., Linliu, S. C., Chang, R. C. Y., \& Mak, A. H. N. (2020). Disaster prevention management in the hotel industry: Hotel disaster prevention literacy. Journal of Hospitality and Tourism Management. https://doi.org/10.1016/j.jhtm.2020.09.008

UNISDR. (2009). 2009 UNISDR Terminologi on Disaster Risk Reduction. the United Nations International Disaster Disaster risk Disaster risk management Strategy for Disaster Reduction (UNISDR) Disaster risk reduction Disaster risk red.

Wahyuningtyas, N., Tanjung, A., Kodir, A., \& Wijanarko, H. (2020). Management of Tourism Areas Based on Disaster Mitigation (Case Study of Senggigi Beach). IOP Conference Series: Earth and Environmental Science, 412(1), 12015. https://doi.org/10.1088/17551315/412/1/012015

Wulung, S. R. P., \& Abdullah, C. U. (2020). Upaya Mitigasi Pasca Tsunami Di Destinasi Pariwisata. Media Bina Ilmiah, 14(7), 2883-2894.

Wulung, S. R. P., Abdullah, C. U., \& Ervina, E. (2019). Post-Disaster Management in Tourism Destination: A Case of Tanjung Lesung, Indonesia. Proceedings The 2019 International Conference on Culture, Technology, and Tourism (CTT), 1. 